\title{
Flammability of diene rubbers
}

\author{
Grażyna Janowska • Agnieszka Kucharska-Jastrząbek • \\ Przemysław Rybiński • Dorota Wesołek • \\ Iwona Wójcik
}

Received: 4 January 2010/ Accepted: 20 May 2010/Published online: 4 June 2010

(C) The Author(s) 2010. This article is published with open access at Springerlink.com

\begin{abstract}
This paper presents the results of testing the flammability and fire hazard of butadiene (BR), butadieneacrylonitrile (NBR) and butadiene- styrene (SBR) rubbers with the use of oxygen index test, ignition temperature measurement, cone calorimetry and inverse liquid chromatography. Toxicometric indices, RTFH $\mathrm{CO} / \mathrm{CO} 2$, $\mathrm{W}_{\mathrm{LC50SM}}$ and the concentration of polycyclic aromatic hydrocarbons (PAH) have been determined. The results obtained have been interpreted from the point of view of the chemical constitution of the polymers tested.
\end{abstract}

Keywords Diene elastomers - Flammability ·

Oxygen index (OI) method · Fire hazard .

Cone calorimetry $\cdot$ Smoke emission .

Toxicometric indices .

Polycyclic aromatic hydrocarbons (PAH)

G. Janowska $\cdot$ A. Kucharska-Jastrząbek

Institute of Polymer and Dye Technology, Technical University

of Łódź, Lodz, Poland

P. Rybiński ( $\square)$

Department of Management and Protection Environment, Jan Kochanowski University of Humanities and Sciences in Kielce, Kielce, Poland

e-mail: przemek100@ujk.kielce.pl

D. Wesołek

Institute of Natural Fibres and Medicinal Plants, Poznan, Poland

I. Wójcik

Institute of Geography, Jan Kochanowski University

of Humanities and Sciences in Kielce, Kielce, Poland

\section{Introduction}

Polymers and polymeric materials are now commonly used in all the fields of economy (industry, agriculture, housing, land, sea, and air transports). In most cases polymers are flammable products. There is a group of polymers such as polyolefines, cellulose, and others that undergo complete combustion in a medium that is poorer in oxygen than atmospheric air. Only few polymers, designed for special applications, can be accepted as inflammable or flameretardant due to their chemical composition and molecular structure. Generally speaking, the flammability of polymers depends on the content of carbon and hydrogen in their macromolecule, which ranges from over $85 \%$ of $\mathrm{C}$ and $14 \%$ of $\mathrm{H}$ to $0 \%$ of hydrogen, e.g., in inflammable nitrozofluoric polymers. The reduction in the flammability of polymeric materials and fire hazard resulting from their use consists in selecting properly the composition of polymeric blends, which can be achieved by using appropriately selected flame-retardant compounds and fillers or nano-fillers, surface modification of components or products. Studies on the preparation of polymeric composites and nano-composites that would be thermally stable and show limited flammability or self-extinguishing capability constitute now one of the more dynamically developed trends in material engineering.

The combustion process of solids can proceed according to the hetero- or homo-phase mechanism depending on their structure. The hetero-phase combustion consists in adsorbing oxygen on the material surface under combustion and flame-less oxidation at the interface. The combustion according to the homo-phase mechanism results from the reaction between the volatile products of thermal decomposition and oxygen with no interfacial surface between reagents $[1,2]$. Generally in polymers, their 
combustion proceeds according to an intermediate mechanism with visible features of homo-phase and heterophase combustions.

The combustion of elastomers is a complex process that depends on the chemical constitution and physical structure of macromolecules as well as on the chemical reactions and physical phenomena taking place in the sample under testing, its boundary layer and flame.

The present article contains a fragment of studies associated with the flammability and fire hazard of butadiene, butadiene-acrylonitrile and butadiene-styrene rubbers commonly used in the rubber industry.

\section{Experimental}

\section{Materials}

The diene rubbers used in our studies included: cis1,4-polybutadiene, SKD II, containing $87-93 \%$ of cis 1,4 mers, made in Russia (BR), butadiene-styrene rubber, KER 1500 , containing $23.5 \%$ of styrene, from Synthos S.A. (SBR) and butadiene-acrylonitrile rubber, Perbunan 2255VP, containing $22 \%$ of acrylonitrile, from Lanxess (NBR).

\section{Methods}

The flammability of elastomers was determined by the method of oxygen index using an apparatus of our own construction [3]. For flammability tests, samples of dimensions $100 \times 10 \times 4 \mathrm{~mm}$ were prepared. Using a constant rate of nitrogen flow amounting to $400 \mathrm{l} / \mathrm{h}$, the oxygen flow rate was selected so that a $50 \mathrm{~mm}$ sample length burned within time $t=180 \mathrm{~s}$. The sample top was ignited for $15 \mathrm{~s}$ by means of a gas burner supplied with a propane-butane mixture [4-6]. The value of oxygen index (OI) was expressed in fractions on the basis of the oxygen volume fraction in the oxygen-nitrogen mixture.

The determinations of flammability in air were also performed, measuring the combustion time of samples whose shape, dimensions, and location as well as ignition time were the same as those in the case of the oxygen index method [4-6]. It was quite difficult to prepare shaped samples for flammability measurements due to their adhesion to the metal mold, but this problem was solved by subjecting the elastomers tested to slight cross-linking by means of dicumyl oxide.

The flammability of the polymers under testing was also determined by the method of cone calorimeter according to standard ISO 5660-1.2002, using an apparatus from Atlas Electric Devices Company. This apparatus is used for integrated tests of materials in terms of their fire characteristics.
Elastomer samples of dimensions $(100 \times 100 \pm 1) \mathrm{mm}$ and thickness $(2.0 \pm 0.5) \mathrm{mm}$, conditioned to constant weight at a temperature of $(20 \pm 0.5){ }^{\circ} \mathrm{C}$ and $\mathrm{RH}(50 \pm 0.5) \%$, were tested in a horizontal position using a heat radiation flux with a density of $35 \mathrm{~kW} / \mathrm{m}^{2}$. During testing the following parameters were recorded: initial sample weight, time for ignition, sample weight during the test, the temperature of inlet gases and their pressure and the concentrations of $\mathrm{O}_{2}$, $\mathrm{CO}_{2}$, and $\mathrm{CO}$ in outlet gases, extinction coefficient and test duration. The time for ignition means the moment from the beginning of test, when the flame lasts at least for $10 \mathrm{~s}$.

The temperature of ignition $\left(T_{\mathrm{Z}}\right)$, determined as the lowest temperature, at which a polymer sample heated in a strictly specified way releases a sufficient quantity of gases to produce a mixture with air that ignites from the flame of a gas burner, was determined by means of an apparatus from ANKO. Disintegrated rubber samples, $0.5 \mathrm{~g}$ in weight, were placed in acid resistant steel test-tubes equipped with metallic lids with holes for gas to escape from the heated material. The test-tubes were electrically heated in an aluminum block within the temperature range $150-400{ }^{\circ} \mathrm{C}$.

The combustion heat of elastomers was determined by means of a bomb calorimeter.

The composition of boundary layer was determined from the results of elementary analysis.

The toxicity of the gas products of elastomer decomposition and combustion was assessed from the results obtained by the method of cone calorimetry $\left(\mathrm{RTFH}_{\mathrm{CO} / \mathrm{CO}_{2}}\right)$ and on the basis of the quantitative chemical determination of the specific emission of $\mathrm{CO}, \mathrm{CO}_{2}, \mathrm{HCN}, \mathrm{NO}_{2}, \mathrm{HCl}$, and $\mathrm{SO}_{2}$ at temperatures of 450,550 , and $750{ }^{\circ} \mathrm{C}$, according to standard PN-B-02855:1988 ( $\left.W_{\text {LC50SM }}\right)$.

The polycyclic aromatic hydrocarbons (PAH) were determined in the rubbers tested and in the gaseous products of their thermal decomposition. For that end elastomers were extracted with acetone for $48 \mathrm{~h}$ at room temperature and the extract obtained was analyzed for the content of PAH. The gaseous products of elastomer thermal decomposition were obtained by their pyrolysis performed in glass pyrolytic test-tubes. The pyrolysis products were transferred by means of a rubber hose to a glass scrubber containing acetone. The determination of 11 PAHs was carried out the method of liquid chromatography in the inverted phase system. The HPLC Lachrom system (Merck Hitachi) consisted of L-7100 isocratic pump, UV L-7400 detector and LiChrospher $100 \mathrm{RP}-185 \mu \mathrm{m}$ column (Merck). The analysis was performed by the method of standard addition (PAH Calibration Mix-Supelco) under the following conditions: $20 \mu \mathrm{l}$ of sample, the mobile phase: acetonitrile-water $(75: 25)$, flow rate: $1 \mathrm{~mL} / \mathrm{min}$, detection at $280 \mathrm{~nm}$. Reagents with HPLC purity were provided by Merck. 


\section{Results and discussion}

The combustion of most elastomers is accompanied by the formation of considerable amounts of liquid products of their thermal decomposition, which flowing down along the sample transfer heat and increase contact with oxygen. These phenomena, considerably impeding the measurements of flammability, take place especially during the combustion of those polymers that are, above all, degraded under the influence of elevated temperatures $[2,7]$.

Our tests have shown that they occur to a limited extent in the case of investigated diene rubbers and to the largest extent during the combustion of polybutadiene. The elastomers under investigation are susceptible to thermal crosslinking; moreover, SBR rubber and especially NBR, due to strong intermolecular interactions as shown by their cohesion energy density, are susceptible to form solid products of thermal decomposition, which facilitates carbonization processes (Table 1). The susceptibility to thermal cross-linking and especially that to form solid products of thermal decomposition significantly influences the structure of boundary layer between the solid and gaseous zones of combustion. The structure of this layer plays an important part in combustion processes as the transport of mass and energy between flame and sample proceeds through this layer. In the case of BR, the boundary layer consists of a cross-linked polymer and a small quantity of liquid destruction products. During the combustion of SBR, and especially NBR, the boundary layer is more thermally stable and porous as it is formed from both the cross-linked and partially carbonized elastomers. Therefore, this layer impedes the flow of mass and energy to a larger extent.

For that reason NBR is characterized by the lowest flammability from among the rubbers investigated, determined by both OI and combustion time in air $\left(t_{\mathrm{s}}\right)$ (Table 1$)$.
The lowest flammability of NBR results also from the comparative analysis of combustion heats of the elastomers tested as in most cases a higher combustion heat corresponds to a higher flammability (Table 1) [8].

BR and SBR rubbers are characterized by comparative flammability determined by OI and $t_{\mathrm{s}}$, but the ignition temperature of SBR is the highest among those of the polymers under investigation.

A significant influence on the polymer flammability is exerted by both the rate of mass loss during combustion and the type of the products being formed. Among the polydienes tested the lowest rate of mass loss is shown by NBR (Table 2). Thus, in the case of this elastomer, the lowest quantity of volatile and flammable products of its thermal decomposition enter the flame through the boundary layer. Moreover, during the destruction processes of NBR nitrogen can be released [1] to form nitrogen compounds as confirmed by the test results of flammability (Table 4). Especially nitrogen but also its compounds reduce the yield of free radical combustion reactions taking place in flame, which is also the reason why NBR shows the lowest flammability in comparison to that of $\mathrm{BR}$ or SBR.

The formation of flammable gaseous products sustaining the combustion of polymers and polymeric materials proceeds due to their thermal decomposition. From the review of scientific literature it follows that in addition to conduction, convection and radiation, a considerable source of heat energy indispensible for sustaining the decomposition of polymers can come from the strongly exothermic oxidative reactions taking place due to the chemisorption of oxygen in the boundary layer between the solid and gaseous phase of combustion [2]. Our test results show that these reactions exert a considerable effect on the combustion processes of the rubbers under investigation,

Table 1 The results of diene rubbers flammability investigations

\begin{tabular}{|c|c|c|c|c|c|c|}
\hline Sample & $\begin{array}{l}\text { Cohesive energy density } \\
(\mathrm{CED}) / \mathrm{MJ} \times \mathrm{m}^{-3},[7,8]\end{array}$ & $\begin{array}{l}\text { Heat of } \\
\text { combustion } / \mathrm{kJ} \times \mathrm{kg}^{-1}\end{array}$ & $T_{\mathrm{z}} /{ }^{\circ} \mathrm{C}$ & OI & $T_{\mathrm{S}} / \mathrm{s}$ & Composition of boundary layer $/ \%^{\mathrm{a}}$ \\
\hline NBR & 432 & 39,600 & 335 & 0.265 & 300 & $\begin{array}{l}\mathrm{C}=70.02 ; \mathrm{H}=8.23 \\
\mathrm{~N}=4.44 ; \mathrm{S}=1.2 ; \mathrm{O}=16.11\end{array}$ \\
\hline SBR & 335 & 43,400 & 348 & 0.260 & 206 & $\begin{array}{l}C=71.83 ; H=8.60 \\
S=0.43 ; O=19.14\end{array}$ \\
\hline BR & 288 & 43,300 & 336 & 0.259 & 180 & $\begin{array}{l}\mathrm{C}=73.48 ; \mathrm{H}=7.95 \\
\mathrm{O}=18.57\end{array}$ \\
\hline
\end{tabular}

$\bar{a}$ The results of elementary analysis of boundary layer after $30 \mathrm{~s}$ of elastomer being under combustion in air. The boundary layer was separated from the sample in depth $\leq 1.0 \mathrm{~mm}$. The results of elementary analysis of investigated elastomers

NBR: $\mathrm{C}=82.93 ; \mathrm{H}=9.39 ; \mathrm{S}=1.57 ; \mathrm{O}=0.52$

SBR: $\mathrm{C}=88.46 ; \mathrm{H}=10.29 ; \mathrm{S}=0.54 ; \mathrm{O}=0.71$

BR: $C=88.60 ; \mathrm{H}=10.79 ; \mathrm{S}=0.51 ; \mathrm{O}=0.10$ 
Table 2 The means values of parameters of diene rubbers determined by cone calorimeter

\begin{tabular}{|c|c|c|c|}
\hline Parameter & NBR & SBR & $\mathrm{BR}$ \\
\hline Time to sustained ignition/s & 50.9 & 70.96 & 67.17 \\
\hline Average heat release rate $/ \mathrm{kW} \times \mathrm{m}^{-2}$ & 1408.23 & 975.65 & 757.81 \\
\hline Peak heat release rate $/ \mathrm{kW} \times \mathrm{m}^{-2}$ & 3362.76 & 2248.28 & 3787.89 \\
\hline Total heat release $/ \mathrm{MJ} \times \mathrm{m}^{-2}$ & 98.71 & 87.88 & 84.5 \\
\hline Average effective heat of combustion/MJ $\times \mathrm{m}^{-2}$ & 51.09 & 34.81 & 42.12 \\
\hline Average mass loss rate/gs $\times \mathrm{m}^{-2}$ & 40.71 & 50.40 & 58.24 \\
\hline Maximum mass loss rate/gs $\times \mathrm{m}^{-2}$ & 71.88 & 66.21 & 79.24 \\
\hline Average specific extinction area $/ \mathrm{m}^{2} \times \mathrm{kg}^{-1}$ & 717.9 & 1098.53 & 772.83 \\
\hline Average $\mathrm{CO}$ yield $/ \mathrm{kg} \times \mathrm{kg}^{-1}$ & 0.091 & 0.082 & 0.1198 \\
\hline Average $\mathrm{CO}_{2}$ yield $/ \mathrm{kg} \times \mathrm{kg}^{-1}$ & 3.153 & 2.43 & 3.0199 \\
\hline
\end{tabular}

regardless of their chemical constitution as indicated by the oxygen-rich boundary layers (Table 1). The lowest contribution of oxygen chemisorption was found in the case of NBR.

The oxygen index method is commonly used to test the flammability of polymers. However, it should be stressed that the values of OI can be used only in the case of comparative assessment of flammability, but they cannot be a base to classify materials with respect to fire hazard. So far no ideal method has been found for testing polymer properties that would decide about their fire hazard. It is accepted that the basic properties characterizing the behavior of polymers under fire conditions include: ignitability described as ignition time, total emitted heat, smoke emission described by its mass average optical density, and the toxicity of the products of thermal decomposition and combustion. These properties can be determined on the basis of test results obtained by the method of cone calorimetry (Tables 2, 3, 4). The comparative analysis of tests presented in Table 2, leads to a conclusion that NBR, showing the lowest flammability among those of the remaining elastomers tested, poses also the smallest fire hazard from the point of view of smoke emission. However, taking into account the total heat emitted and the average and maximum rates of heat emission, its fire hazard is greater than those of BR and SBR. The highest quantity of emitted smoke is shown by SBR due to the content of aromatic groups in its macromolecules.

Fire hazard results also from oxygen consumption during the combustion of polymers or polymeric materials.

Table 3 The diene rubbers properties describing their behaviour in the fire conditions

\begin{tabular}{llll}
\hline Parameter & NBR & SBR & BR \\
\hline $1 / t_{\text {flashover }}, \mathrm{kW} \times \mathrm{m}^{-2} \mathrm{~s}^{-1}$ & 66.06 & 31.68 & 56.37 \\
$\mathrm{RTFH}_{\mathrm{CO} / \mathrm{CO}_{2}}$ & 0.0339 & 0.0236 & 0.0406 \\
\hline
\end{tabular}

Our test results show that from this point of view, the smallest fire hazard is posed by SBR (Fig. 1).

The results obtained by the method of cone calorimetry (Table 2) were used to determine the fire hazard connected with the fire propagation rate, $1 / t_{\text {flashover }}$ i.e., inverse time to achieve flashover according to Eq. 1 and the toxicity of gaseous products of thermal decomposition and combustion described by the value of relative toxic fire hazard, $\mathrm{RTFH}_{\mathrm{CO} / \mathrm{CO}_{2}}$ connected with carbon oxide and dioxide according to Eq. 2 (Table 3).

$\frac{1}{t_{\text {flashover }}}=\frac{\mathrm{HRR}_{\text {max }}}{\mathrm{TTI}}$

where $t_{\text {flashover }}$ is the fire propagation rate, inverse time to reach the effect of flashover, $\mathrm{HRR}_{\max }$ is the peak heat release rate (Table 2), and TTI is time to sustained ignition (Table 2)

$\mathrm{RTFH}_{\mathrm{CO} / \mathrm{CO}_{2}}=\frac{\mathrm{MLR}}{\mathrm{TTI}}\left(\frac{\mathrm{CO} \text { Yield }}{\mathrm{LC}_{50}^{30} \mathrm{CO}}+\frac{\mathrm{CO}_{2} \text { Yield }}{\mathrm{LC}_{50}^{30} \mathrm{CO}}\right)$

where MLR is the average mass loss rate, $\mathrm{CO}$ Yield is the average $\mathrm{CO}$ yield, $\mathrm{CO}_{2}$ Yield is the average $\mathrm{CO}_{2}$ yield, and $\mathrm{LC}_{50}^{30} \mathrm{CO} ; \mathrm{LC}_{50}^{30} \mathrm{CO}_{2}$ is the lethal concentration respectively $\mathrm{CO}$ and $\mathrm{CO}_{2}$ to cause a $50 \%$ lethality of testing animals during $30 \mathrm{~min}$ exposure.

The analysis of results listed in Table 3, leads to a conclusion that butadiene and nitrile rubbers pose a considerably greater fire hazard expressed by the values of both $1 / t_{\text {flashover }}$ and $\mathrm{RTFH}_{\mathrm{CO} / \mathrm{CO} 2}$ in relation to butadiene-styrene rubber. It should be clearly mentioned that the diene rubbers tested by us pose a greater fire hazard than that of the commonly used polyolefines such as polyethylene (PE) and polypropylene (PP). The values of $1 / t_{\text {flashover }}$ of $\mathrm{PE}$ and PP amount to 20.15 and 44.22, respectively, and those of $\mathrm{RTFH}_{\mathrm{CO} / \mathrm{CO}_{2}}$ equal to 0.0051 and 0.0138 , respectively $[9,10]$.

The toxicity of the products of thermal decomposition and combustion of vulcanizates depends not only on the 
Table 4 The results of toxicity investigations of the products of thermal decomposition and flammability of diene rubbers

\begin{tabular}{|c|c|c|c|c|c|c|c|c|c|c|}
\hline \multirow[t]{2}{*}{ Sample } & \multirow[t]{2}{*}{ Temperature $/{ }^{\circ} \mathrm{C}$} & \multicolumn{6}{|c|}{ Emission, $\mathrm{mg} / \mathrm{g}$} & \multirow[t]{2}{*}{ Ratio $\mathrm{CO}_{2} / \mathrm{CO}$} & \multicolumn{2}{|c|}{ Toxicometric Index } \\
\hline & & $\mathrm{HCN}$ & NO & $\mathrm{NO}_{2}$ & $\mathrm{CO}$ & $\mathrm{SO}_{2}$ & $\mathrm{CO}_{2}$ & & $\mathrm{~W}_{\mathrm{LC50M}}$ & $\mathrm{W}_{\mathrm{LC} 50 \mathrm{SM}}$ \\
\hline \multirow[t]{3}{*}{ NBR } & 450 & 17.02 & 5.71 & 0.00 & 69.37 & 7.88 & 431.85 & 6.22 & 7.23 & 9.13 \\
\hline & 550 & 8.09 & 4.41 & 0.80 & 201.7 & 12.73 & 1752.26 & 8.68 & 7.38 & \\
\hline & 750 & 3.63 & 8.19 & 2.95 & 93.16 & 0.71 & 2980.66 & 31.99 & 12.79 & \\
\hline \multirow[t]{3}{*}{ SBR } & 450 & - & - & - & 58.57 & 26.16 & 115.56 & 1.97 & 18.66 & 17.25 \\
\hline & 550 & - & - & - & 190.4 & 9.405 & 2243.62 & 11.78 & 13.22 & \\
\hline & 750 & - & - & - & 99.39 & 8.627 & 2254.36 & 22.68 & 19.88 & \\
\hline \multirow[t]{3}{*}{$\mathrm{BR}$} & 450 & - & - & - & 126.2 & 58.57 & 55.07 & 0.43 & 14.12 & 19.65 \\
\hline & 550 & - & - & - & 266.9 & 190.4 & 4068.8 & 15.24 & 8.31 & \\
\hline & 750 & - & - & - & 21.47 & 99.39 & 3964.54 & 184.65 & 36.52 & \\
\hline
\end{tabular}

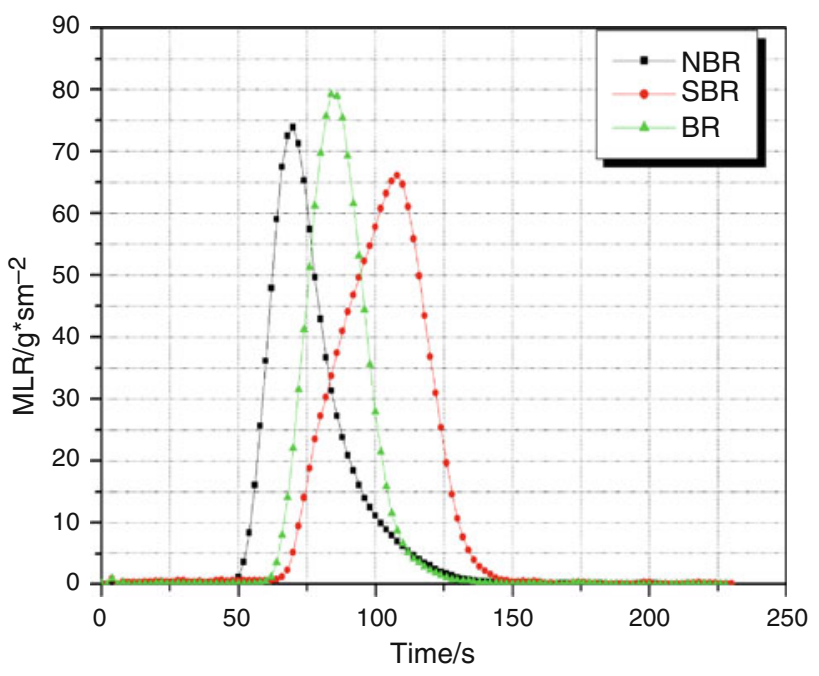

Fig. 1 The mass loss rate of diene rubbers determinated by cone calorimeter

emission of $\mathrm{CO}$ and $\mathrm{CO}_{2}$, but also on the emission of other gaseous products such as $\mathrm{HCN}, \mathrm{NO}, \mathrm{NO}_{2}$, and $\mathrm{SO}_{2}$. The parameter that takes into account the concentrations of all the six gases emitted at temperatures $T=450,550$, and $750{ }^{\circ} \mathrm{C}$ is known as toxicometric index, $W_{\mathrm{LC} 50 \mathrm{SM}}$, described by Eq. $3[11,12]$.

$W_{\mathrm{LC} 50 \mathrm{SM}}=\frac{W_{\mathrm{LC} 50 \mathrm{M} 450}+W_{\mathrm{LC} 50 \mathrm{M} 550}+W_{\mathrm{LC} 50 \mathrm{M} 750}}{3}$

$W_{\mathrm{LC50SM}}$ index is a arithmetic average of $W_{\mathrm{LC50M}(\mathrm{T})}$ indices

$\frac{1}{W_{\mathrm{LC} 50 \mathrm{M}(T)}}=\sum^{n} \frac{1}{W_{\mathrm{LC} 50}}$

where $n$ is the number of gaseous products, $W_{\mathrm{LC50}}$ is the maximum toxic concentration of gaseous product forming during thermal decomposition, and combustion of testing material in the " $T$ " temperature.
$W_{\mathrm{LC} 50}=\frac{\mathrm{LC}_{50}^{30}}{E}$

where $E$ is the emission, $\mathrm{g} / \mathrm{g}, \mathrm{LC}_{50}^{30}$ is the lethal concentration of gaseous product of thermal decomposition and combustion of testing material which cause a $50 \%$ lethality of testing animals during $30 \mathrm{~min}$ exposure.

According to standard PN-B-02855:1988 the value of $\mathrm{W}_{\mathrm{LC50SM}}$ is the base of classifying the products of thermal decomposition and combustion into the following groups:

$\mathrm{W}_{\mathrm{LC50SM}} \leq 15$-very toxic products

$15 \leq \mathrm{W}_{\mathrm{LC50SM}} \leq 40$-toxic products

$\mathrm{W}_{\mathrm{LC50SM}}>40$-moderately toxic products

From the toxicometric indices determined it follows that butadiene rubber and butadiene-styrene rubber belong to the group of toxic polymers, while butadiene-acrylonitrile rubber belongs to the group of very toxic polymers. The considerably higher value of $W_{\mathrm{LC} 50 \mathrm{SM}}$ of NBR in comparison to those of $\mathrm{BR}$ and $\mathrm{SBR}$ is associated with the emission of $\mathrm{NO}, \mathrm{NO}_{2}$, and $\mathrm{HCN}$ (Table 4).

In recent years increasingly high importance has been ascribed to the problem of the emission of PAH formed during the thermal decomposition and combustion of polymers and polymeric materials as well as those contained in polymers. Based on the analyses performed by the method of liquid chromatography, we have determined the concentrations of 11 best known polycyclic compounds in the gaseous products of the thermal decomposition and combustion of diene rubbers (Table 5). The highest concentrations of acenaphthylene, fluorene and carcinogenic dibenzo(a,h)anthracene consisting of five condensed rings are observed in BR. The high concentrations of PAH in the process of $\mathrm{BR}$ thermal decomposition result from the fact that the macromolecules of BR contain $87-93 \%$ mers with a cis 1-4 structure. During the initial stage of pyrolysis butadiene mers react, according to Diels-Alder's mechanism, with alkanes $\left(\mathrm{C}_{1}-\mathrm{C}_{3}\right)$ and alkenes $\left(\mathrm{C}_{2}-\mathrm{C}_{6}\right)$, 
Table 5 Polycyclic aromatic hydrocarbons in $\mu \mathrm{g} /$ mass sample in the gaseous products from the thermal decomposition and combustion of diene rubbers

\begin{tabular}{|c|c|c|c|c|}
\hline Sample & BR & SBR & NBR & $\begin{array}{l}\text { Amount } \\
\text { condensed rings }\end{array}$ \\
\hline Naftalen & 3.005348 & 35.08016 & 5.633333 & 2 \\
\hline Acenaftylen & 133.1717 & 29.54545 & - & 2 \\
\hline Acenaften & 2.801264 & 143.0447 & - & 2 \\
\hline Fluoren & 23.84917 & 8.793478 & 4.196217 & 2 \\
\hline Fenantren & - & 24.09389 & 4.587242 & 3 \\
\hline Fluoranten & - & 4.83871 & 12.04918 & 3 \\
\hline Piren & 1.599166 & 12.73466 & 1.53944 & 4 \\
\hline Benzo(b)Fluoranten & 1.373562 & 2.328704 & 6.787745 & 4 \\
\hline Benzo(k)Fluoranten & 1.678937 & 3.16289 & 4.617404 & 4 \\
\hline Benzo(a)Piren & 2.777143 & 0.999265 & 6.90447 & 5 \\
\hline Dibenzo(a,h)Antracen & 3.021656 & 2.030371 & 5.112 & 5 \\
\hline
\end{tabular}

Mass sample $2 \mathrm{mg}$

previously resulted from destruction processes, to form basis aromatic compounds such as benzene, toluene, or styrene [13-15].

Then PAH are formed as a result of mutual condensation of aromatic rings or subsequent reactions between aromatic compounds and olefins. Considerably lower concentrations of PAH in the thermal decomposition products of SBR and NBR result from lower contents of diene mers in their macromolecules, and in the case of nitrile rubber, also from the proceeding processes of carbonization. According to our opinion the relatively high concentrations of naphthalene, acenaphthylene, acenaphthene and phenanthrene in the case of butadiene-styrene rubber can be connected with the modification of this elastomer with naphthene oils, which undoubtedly are their precursors [16].

Table 6 Polycyclic aromatic hydrocarbons in $\mu \mathrm{g} / \mathrm{mass}$ sample in pure diene rubbers

\begin{tabular}{lllll}
\hline Sample & BR & SBR & NBR & $\begin{array}{l}\text { Amount } \\
\text { condensed } \\
\text { rings }\end{array}$ \\
\hline Naftalen & & & & 2 \\
Acenaftylen & - & - & 0.3759 & 2 \\
Acenaften & 0.1412 & - & 0.0775 & 2 \\
Fluoren & - & - & 0.0712 & 2 \\
Fenantren & 0.0583 & 0.2323 & 0.0802 & 3 \\
Fluoranten & - & - & - & 3 \\
Piren & - & 0.1846 & - & 4 \\
Benzo(b)Fluoranten & - & - & - & 4 \\
Benzo(k)Fluoranten & - & - & - & 4 \\
Benzo(a)Piren & - & - & - & 5 \\
Dibenzo(a,h)Antracen & - & - & - & 5
\end{tabular}

Mass sample $2 \mathrm{mg}$
Our test results show that PAH are also present in the rubbers under investigation (Table 6). The concentrations of PAH in this case are however low, connected with the presence of two- and three-cyclic compounds, whose carcinogenic effects are considerably weaker in comparison with compounds consisting of a higher number of condensed rings. Thus, the use of these polymers does not pose a health hazard. A big hazard occurs under fire conditions as PAH are formed first of all in the processes of thermal decomposition and combustion of the rubber under investigation.

\section{Conclusions}

Among the diene rubbers tested, butadiene-acrylonitrile rubber is characterized by the lowest flammability determined by OI and $t_{\mathrm{s}}$; this rubber poses also the smallest fire hazard from the point of view of smoke emission. However, the products of its decomposition and combustion show the highest degree of toxicity $\left(W_{\text {LC50SM) }}\right.$.

Conduction, convection, and radiation not constitute the basic source of heat energy indispensable to sustain the thermal decomposition of the rubbers during their combustion. A considerable role is played also by exothermic reactions in the boundary layer between solid and gaseous phases. These reactions take place to the smallest extent in NBR.

The products of thermal decomposition of the polydienes tested include also PAH.

Open Access This article is distributed under the terms of the Creative Commons Attribution Noncommercial License which permits any noncommercial use, distribution, and reproduction in any medium, provided the original author(s) and source are credited. 


\section{References}

1. Troitzch J. International plastics flammability handbook. Munich, Viena, New York: Hanser Publishers; 1990.

2. Janowska G, Przygocki W, Włochowicz A. Palność polimerów i materiałów polimerowych. Warszawa: WNT; 2007.

3. Ślusarski L, Janowska G, Szkodziński A, Niedomagała M, Harwaziński A. Układ do pomiaru wskaźnika tlenowego tworzyw sztucznych, naturalnych lub gumy, Patent PRL 129411. 1987.

4. Ślusarski L, Janowska G. Palność elastomerów. Polimery. 1982;27:13.

5. Babrauskas V. Describing product fire performance-manufacturers, versus modelers needs. Fire Mater. 1994;18:289.

6. Rybiński P, Janowska G, Helwig M, Dąbrowski W, Majewski K. Flammability of butadiene-acrylonitrile rubbers. J Therm Anal Calorim. 2004;75:249.

7. Janowska G. Thermal stability and flammability of elastomers. Zeszyty Naukowe Politechniki Łódzkiej, Łódź. 1998;801:1-107.

8. Johnson PR. A general correlation of the flammability of natural and synthetic polymers. J Appl Polym Sci. 1974;18:491.

9. Helwig M, Paukszta D. Flammability of composites based on polypropylene and flax fibres in molecular crystal and liquid crystal, vol 354. Philadelphia: Gordon and Breach Science Publisher; 2000

10. Paukuszta D, Borysiak S. Structure of isotactic polypropylene in composites with natural fibres obtained in various processing methods. Fibres Text. 2005;53:107-9.

11. Janowska G, Rybiński P, Krauze S. The effect of the curing agent type on the flammability of butadiene-acrylonitrile rubbers. Polimery. 2006;51:735.

12. Rybiński P, Janowska G, Antkiewicz W, Krauze S. Thermal stability and flammability of butadiene-acrylonitrile rubber crosslinked with iodoform. J Therm Anal Calorim. 2005;81:9.

13. Cypres R, Braekman-Danheux C, Delaunois C, Halloin V. Aromatisation of 1,3-butadiene under pressure. Thermochem Acta. 1991;179:99.

14. Williams PT, Bottril RP. Sulfur-polycyclic aromatic hydrocarbons in tyre pyrolysis oil. Fuel. 1995;74:736.

15. Wang Z, Li K, Lambert P, Yang C. Identification, characterization and quantitation of pyrogenic polycylic aromatic hydrocarbons and other organic compounds in tire fire products. J Chromatogr A. 2007;1139:14.

16. Stang G. Oleje naftenowe mniej rakotwórcze. Elastomery. 2001;1:3. 